\title{
Erythrocyte Pyruvate Kinase Deficiency mutation identified in multiple breeds of domestic cats
}

\author{
Robert A Grahn ${ }^{1 *}$, Jennifer C Grahn², Maria CT Penedo², Chris R Helps ${ }^{3}$ and Leslie A Lyons ${ }^{1}$
}

\begin{abstract}
Background: Erythrocyte pyruvate kinase deficiency (PK deficiency) is an inherited hemolytic anemia that has been documented in the Abyssinian and Somali breeds as well as random bred domestic shorthair cats. The disease results from mutations in $P K L R$, the gene encoding the regulatory glycolytic enzyme pyruvate kinase (PK). Multiple isozymes are produced by tissue-specific differential processing of PKLR mRNA. Perturbation of PK decreases erythrocyte longevity resulting in anemia. Additional signs include: severe lethargy, weakness, weight loss, jaundice, and abdominal enlargement. In domestic cats, PK deficiency has an autosomal recessive mode of inheritance with high variability in onset and severity of clinical symptoms.

Results: Sequence analysis of PKLR revealed an intron 5 single nucleotide polymorphism (SNP) at position 304 concordant with the disease phenotype in Abyssinian and Somali cats. Located 53 nucleotides upstream of the exon 6 splice site, cats with this SNP produce liver and blood processed mRNA with a 13 bp deletion at the 3' end of exon 5. The frame-shift mutation creates a stop codon at amino acid position 248 in exon 6 . The frequency of the intronic SNP in 14,179 American and European cats representing 38 breeds, 76 western random bred cats and 111 cats of unknown breed is $6.31 \%$ and $9.35 \%$ when restricted to the 15 groups carrying the concordant SNP.

Conclusions: PK testing is recommended for Bengals, Egyptian Maus, La Perms, Maine Coon cats, Norwegian Forest cats, Savannahs, Siberians, and Singapuras, in addition to Abyssinians and Somalis as well an any new breeds using the afore mentioned breeds in out crossing or development programs.
\end{abstract}

Keywords: PKLR, Pyruvate kinase liver and RBC, Pyruvate kinase deficiency, PK deficiency, Feline, Cat, Anemia

\section{Background}

During maturation of mammalian erythrocytes, the nucleus and cellular organelles are lost [1,2]. Thus, the mature erythrocytes lack DNA and are unable to produce RNA, rendering them incapable of division and repair and limiting the functional lifespan of the circulating red blood cell (RBC). Additionally, mitochondrial loss limits ATP production within the RBC to glycolysis. The final ATP yielding step of the Embden-Meyerof glycolytic pathway is the conversion of phosphoenolpyruvate to pyruvate via the regulatory enzyme pyruvate kinase.

Two structural genes encode pyruvate kinase (PK); pyruvate kinase, liver and RBC (PKLR) and pyruvate kinase, muscle (PKM2) [3]. Tissue- and development-specific expression, as well as cellular metabolic needs, determine

\footnotetext{
* Correspondence: ragrahn@ucdavis.edu

'Department of Population Health and Reproduction, School of Veterinary

Medicine, University of California, Davis, CA 95616, USA

Full list of author information is available at the end of the article
}

which of these genes is expressed [4-8]. Additionally, each gene has isozymes generated by alternative splicing of exons 9 and 10 in PKM2 and promoter selection, with the corresponding exon 1 , in PKLR $\mathrm{L}$ and $\mathrm{R}$ alleles $[9,10]$. PKM2 generates the M1 and M2 isozymes. M1-PK is produced in muscle and brain while M2-PK is expressed in retina, lung, fat tissue, pancreas and rapidly dividing cells such as embryonic and tumor cells [11]. In humans, the $\mathrm{L}$ and $\mathrm{R}$ isozymes are PKLR products generated in the liver and reticulocytes, respectively. Homologous sequence data protein prediction algorithms suggest both forms are present in other primates but experimental evidence for two forms is only supported in humans, dogs (NM_001256262.1 and NM001256018.1), mice (NM_013631.2, NM_001099779.1) and rats [12].

Perturbation of PK results in PK deficiency and ultimately leads to hemolytic anemia. In humans, over 190 PK mutations have been identified [13-21]. PK deficiency has also been clinically characterized in several canine

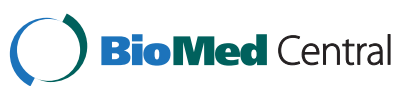


small-breed dogs including: Basenji [22], Beagle [23], Dachshound [24], Cairn Terrier [25], Pug [26], and West Highland White Terrier [27]. To date, affected large breed dogs have been restricted to Labrador Retrievers [26]. An exonic deletion (c.433delC) results in PK deficiency in Basenjis [28], a 6 bp exon 10 insertion is causative in West Highland and Cairn Terriers [26,29], missense mutations c.848T $>C$ and c.994G $>$ A result in Pug and Beagle PK deficiency respectively and Labrador Retrievers have a c.799C $>\mathrm{T}$ mutation that results in a premature termination codon and loss of over $53 \%$ of the protein [26]. It should be noted that not all Labradors with clinical symptoms of PK deficiency have the c.799C > T mutation [26]. Affected dogs present with clinical signs as early as a few months to as late as several years of age regardless of the causative mutation. Disease severity is variable but both Basenjis and Labradors with the c.799C $>\mathrm{T}$ mutation have a more severe anemia and shortened lifespan [26]. The initial sign of the disease commonly presents as exercise intolerance resulting from PK deficiency induced anemia.

Domestic cats also have an inherited PK deficiency. The disease manifests as a chronic, intermittent, hemolytic anemia. Typically, clinical symptoms include but are not limited to: lethargy, diarrhea, pale mucous membranes, lack of appetite, poor coat quality, weight loss, icterus and occasionally splenomegaly. Blood chemistry may reveal anemia, increased aggregated reticulocyte counts, hyperglobulinaemia, hyperbilirubinaemia, and increased liver enzymes (for detailed, longitudinal clinical symptoms see Kohn et al. 2000 and 2008) [30,31]. In a cohort of 25 affected cats, clinical signs first manifested as early as six months and as late as five years. Some cats died or required euthanization while others maintained an adequate quality of life. Thus, both severity of clinical presentation and age of onset are variable.

The first documented report of feline PK deficiency was in an Abyssinian cat [32]. Later, reports demonstrated that Somalis, a longhaired variety of Abyssinians, as well as random bred domestic shorthairs, had PK deficiency. A proceedings abstract implicated a deletion of the last 13 bases of exon 5 of $\mathrm{R}$ type PKLR from liver cDNA in Abyssinian and Somali cats [33]. No correlating genomic deletion was detected but two intron 5 SNPs were mentioned, one of which was concordant with disease. The nature, sequence, and location of the SNPs were not disclosed. No sequence, gene, or SNP data has ever been curated in any publicly available repository regarding PK deficiency. However, subsequent research evaluating geographic distribution and frequency of the PK deficiency SNP in the Abyssinian and Somali breeds, performed in collaboration with the reporting laboratory, cites the proceedings abstract [30,34].
In this study, PKLR mRNA was isolated from whole blood and bone marrow from two cats heterozygous for the historically proposed PK mutation and the generated cDNA was examined in its entirety for additional mutations by sequence analysis. A concordant SNP at position 304 of intron 5 was identified, as well as two, non-correlated SNPs at intronic positions 303 and 320. The disease-associated SNP presence and frequency was determined in 14,179 cats representing 40 breeds or populations. Fifteen groups (defined as a specific breed, samples that could not be assigned to a breed and domestic random bred cats) possess the diagnostic PK deficiency SNP at a frequency of $9.35 \%$.

\section{Methods}

\section{Samples for population frequencies}

Buccal samples from cats $(\mathrm{n}=14,179)$ were submitted to the Veterinary Genetics Laboratory (VGL) ( $\mathrm{n}=$ 12,630) at the University of California at Davis, CA or Langford Veterinary Services (LVS) $(n=1,549)$ at the University of Bristol, UK for genetic testing. Breed identification was owner reported. DNA from VGL submitted samples was isolated as previously described [35]. LVS submitted samples were supplied from owners as buccal swabs and DNA isolated as described previously [36].

\section{RNA and DNA isolation}

Genomic DNA was isolated from peripheral RBC from two cats heterozygous for the putative diagnostic SNP and from a cat homozygous for the SNP but not presenting with clinical signs of anemia. Total RNA was isolated from bone marrow and liver samples from one carrier cat and from RBC of the second carrier cat. Tissues were stored in RNAlater (Qiagen Inc., Valencia CA, USA) at $-20^{\circ} \mathrm{C}$ prior to RNA isolation. All RNA was isolated as previously described [37]. Samples were collected from research animals housed at the Feline Genetics Research Colony at UC Davis under Institutional Animal Care and Use Committee protocol 15177.

\section{Gene analysis}

Feline genomic sequence data for $P K L R$ generated by the feline genome sequencing project (AANG00000000.2) [38] was available for exons 2 and 6 through 11. Primers were designed using Primer3plus (http://www. bioinformatics.nl/cgi-bin/primer3plus/primer3plus.cgi) flanking the exons to obtain splice boundaries (Table 1). No genomic sequence was available in the public database for cat PKLR exons 1, 3, 4, and 5. Complete complementary cDNA was generated using Superscript III first strand synthesis reaction (Invitrogen, Carlsbad, CA) according to manufacturer's gene specific primer protocol. 
Table 1 Genomic and CDNA primers and their locations for PKLR in domestic cats

\begin{tabular}{|c|c|c|c|}
\hline gDNA Primer & 5'-3' Sequence & gDNA Primer & 5'-3' Sequence \\
\hline PKLRex2F & 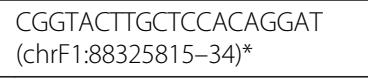 & PKLRex2R & $\begin{array}{l}\text { GTGGCGATGATGCAGGTACT } \\
\text { (chrF1:88326141-60) }\end{array}$ \\
\hline PKLRex5F & $\begin{array}{l}\text { CGAACACCGTGTGGGTAGACTA } \\
\text { (derived from cDNA) }\end{array}$ & PKLRex6R & $\begin{array}{l}\text { GGAGGCAAACACGATGTCTACC } \\
\text { (chrF1:88327517-38) }\end{array}$ \\
\hline PKLRex6F & $\begin{array}{l}\text { TCGTGTTGGCCTCCTTTG } \\
\text { (chrF1:88327525-42) }\end{array}$ & PKLRex10R & $\begin{array}{l}\text { AGACCTCTCGGAACAGGTG } \\
\text { (chrF1:88329412-30) }\end{array}$ \\
\hline PKLRex9F & $\begin{array}{l}\text { TCAAGTGCTGTGCTGCTG } \\
\text { (chrF1:88328580-97) }\end{array}$ & PKLR3utrR & $\begin{array}{l}\text { TGGCCAGTGCTTAATTGG } \\
\text { (chrF1:88330288-305) }\end{array}$ \\
\hline cDNA Primer & 5'-3' Sequence & cDNA Primer & 5'-3' Sequence \\
\hline PKLR_CD_Ex2F & $\begin{array}{l}\text { GGGTACCTACGGCGGGTCAG } \\
\text { (chrF1:88325991-6010) }\end{array}$ & PKLR_CD_EX7R & $\begin{array}{l}\text { CTTCTCAGGTGGGATCTCGAT } \\
\text { (chrF1:88327825-45) }\end{array}$ \\
\hline PKLR_cD_Ex6F & $\begin{array}{l}\text { TCGTGTTTGCCTCCTTTGTGCG } \\
\text { (chrF1:88327525-42) }\end{array}$ & PKLR_CD_Ex10R & $\begin{array}{l}\text { AGACCTCTCGGAACAGGTG } \\
\text { (chrF1:88329412-30) }\end{array}$ \\
\hline PKLR_CD_Ex8F & $\begin{array}{l}\text { GAGACGAGCGATGTAGCG } \\
\text { (chrF1:88328256-73) }\end{array}$ & PKLR_3UTR & $\begin{array}{l}\text { CGTGAAATGGAGCAGGGAAGG } \\
\text { (chrF1:88330247-67) }\end{array}$ \\
\hline 5' Race primer & 5'-3' Sequence & 5' Race primer & 5'-3' Sequence \\
\hline AUAP & GGCCACGCGTCGACTAGTAC & PKLR_5'_ex2/3R & CCGGCCCAATGGTGGCG \\
\hline
\end{tabular}

* locations defined by feline assembly Dec. 2008 NHGRI/GTB V17e/felCat4.

Genomic DNA was amplified for available exons as previously described [39]. All cDNA PCRs were performed as two separate reactions in a total volume of $20 \mu \mathrm{l}$. First round PCRs used $2 \mu \mathrm{l} \mathrm{cDNA}$ as the template while second round reactions used $1 \mu \mathrm{l}$ of the first round amplicons in the following reaction: $2 \mathrm{mM} \mathrm{MgCl}_{2}, 1 \mathrm{X}$ Amplitaq Gold Buffer (Applied Biosystems), $1.25 \mathrm{mM}$ dNTPs, $0.5 \mu \mathrm{M}$ of each primer and 0.75 units of Amplitaq Gold (Applied Biosystems). First round PCR reactions were amplified under the following cycling conditions in a 2720 Thermal cycler (Applied Biosystems): $94^{\circ} \mathrm{C}$ for $4 \mathrm{~min}$ initial denaturation, followed by 5 cycles of $30 \mathrm{sec}$ at $94^{\circ} \mathrm{C}, 2 \mathrm{~min}$ at $72^{\circ} \mathrm{C}$, then 5 cycles of $30 \mathrm{sec}$ at $94^{\circ} \mathrm{C}, 2 \mathrm{~min}$ at $70^{\circ} \mathrm{C}$ and lastly 25 cycles of $30 \mathrm{sec}$ at $94^{\circ} \mathrm{C}, 20 \mathrm{sec}$ at $66^{\circ} \mathrm{C}$ and $2 \mathrm{~min}$ at $72^{\circ} \mathrm{C}$. A $72^{\circ} \mathrm{C}$ final incubation for $10 \mathrm{~min}$ was added to ensure full product length for all amplicons. The second round thermal cycle profile was as follows: $94^{\circ} \mathrm{C}$ for $4 \mathrm{~min}$ initial denaturation, followed by 5 cycles of $30 \mathrm{sec}$ at $94^{\circ} \mathrm{C}, 20$ sec at $64^{\circ} \mathrm{C}$ and $2 \mathrm{~min}$ at $72^{\circ} \mathrm{C}, 5$ cycles of $30 \mathrm{sec}$ at $94^{\circ} \mathrm{C}, 20 \mathrm{sec}$ at $62^{\circ} \mathrm{C}$ and $2 \mathrm{~min}$ at $72^{\circ} \mathrm{C}$ and 25 cycles of $30 \mathrm{sec}$ at $94^{\circ} \mathrm{C}, 20 \mathrm{sec}$ at $60^{\circ} \mathrm{C}$ and $2 \mathrm{~min}$ at $72^{\circ} \mathrm{C}$, with a final extension at $72^{\circ} \mathrm{C}$ for $10 \mathrm{~min}$. PCR products were visualized by agarose gel electrophoresis and prepared and sequenced as previously described [40]. Sequencing products for an individual cat were assembled into a single gene contig using Sequencher analysis software v4.1 (Gene Codes Corporation, Ann Arbor, MI). Assembled contigs from each sample were aligned to identify sequence variants.

The 5 untranslated region and exon 1 sequence data were obtained using the GeneRacer Core Kit (Invitrogen) as previously described [37]. Amplified products were sequenced and assembled as described above.

\section{Results}

The complete PK type- $\mathrm{R}$ transcript sequence was obtained from both a bone marrow and liver sample of a carrier cat. The feline CDS R-type PK transcript is $1,725 \mathrm{bp}$, contains 11 exons, and in silico translation predicts a 574 amino acid protein. Sequence identity to domestic dog, panda and human (GenBank Accession Nos.: NM_001256262.1, XM_002928283, NM_000298, respectively) is $89.9 \%, 89.7 \%$ and $87.6 \%$, respectively, with a protein homology of $89.7 \%, 88.7 \%$ and $88.0 \%$, respectively. A partial PK transcript was obtained from RBC, but because it lacked the 5 ' portion it could not be identified as an R-type or L-type transcript. Multiple attempts failed to obtain the L-type mRNA transcript from liver, bone marrow and RBCs.

Bone marrow and liver RNA from the carrier cat yielded the wild-type- $\mathrm{R}$ transcript as well as a shortened product (GenBank Accession \#s JX951426 and JX951427). The abbreviated transcript is identical to wild-type at the sequence level with the exception of a deletion of the last $13 \mathrm{bp}$ of exon 5 (Figure 1). The same abbreviated transcript was identified in the RBC of a second carrier cat, however, the 5' portion was not obtained. In silico translation of this product results in a frame shift and erroneous translation of the first 20 amino acids of exon 6 , followed by a premature stop codon at position 248 (Figure 1). This truncation results in a loss of the terminal $57 \%$ of the mature PKLR type-R protein. 


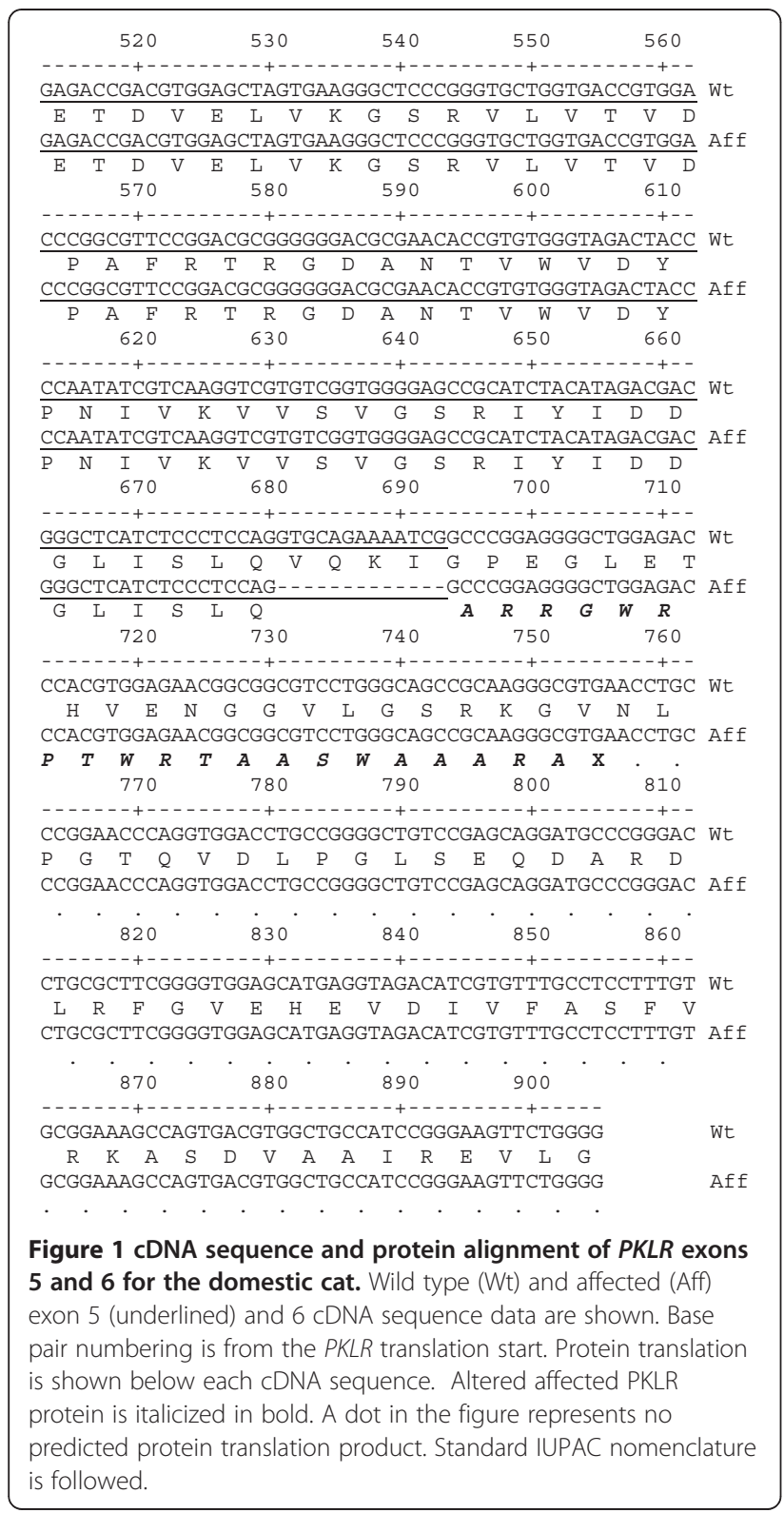

Genomic sequencing of two wild-type, one carrier and the cat homozygous for the putative causative SNP for PKLR exon 5, intron 5 and exon 6 revealed two SNPs in intron 5 at positions 304 and 320; a $\mathrm{G}>\mathrm{A}$ and $\mathrm{C}>\mathrm{T}$, respectively (Figure 2) (GenBank accession \# JX951425). No other polymorphisms were identified in this region or in the other genomic sequence evaluated that included exons 2, 6 - 11, their intronexon boundaries and portions of the flanking intronic regions. The c.693+304G>A mutation was concordant with the cat PK deficiency phenotype, while the c.693 $+320 \mathrm{C}>\mathrm{T}$ mutation was homozygous in cats with no clinical history of anemia and therefore presumed discordant. While typing submitted samples, LVS noted that

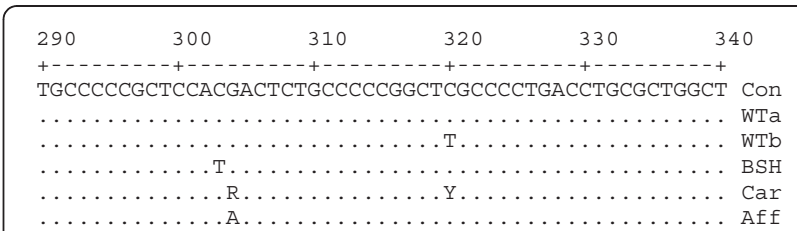

Figure 2 Partial genomic DNA intron 5 sequence of PKLR in the domestic cat. Base pair positions are numbered from the exon 5 splice boundary. The correlated PK deficiency SNP is found at position 304. Three non-affected cats (WTa, WTb, and BSH-British shorthair) are shown as well as a carrier (Car) and affected (Aff). A dot represents positions where the sequence data matched the feline consensus (Con) sequence. Standard IUPAC nomenclature is followed.

British Shorthairs contain a c. $693+303 \mathrm{C}>\mathrm{T}$ mutation on the wild type allele that is discordant with the disease phenotype.

Cat breed samples were submitted by owners to the VGL and LVS for PK deficiency testing, which evaluated the PKLR c.693+304G>A SNP. The cats submitted for DNA testing represented a biased and unbiased sampling for estimation of the SNP frequency (Table 1). Biased samples included those specifically submitted for PK deficiency testing ( $\mathrm{n}=3,084$ - VGL, $\mathrm{n}=1,506$ - LVS) and the unbiased samples were submitted for other catspecific DNA tests ( $\mathrm{n}=9,546-$ VGL, $\mathrm{n}=43-\mathrm{LVS})$. Thirtyseven breeds were submitted to the VGL and six to LVS, representing 38 cat breeds from USA and UK populations. Cat samples submitted to the VGL were primarily from United States sources but also included international submissions.

At least 10 unrelated individual cats were required to represent a population in this study. The c.693+304G>A PK deficiency-associated SNP is present at a frequency of $6.31 \%$ for the entire sample set (Table 2). The c.693+304G $>$ A SNP was detected in 13 breeds, random bred cats and unspecified cats and was absent in 25 breeds. The frequency of the c.693+304.G>A increases to 9.35\% when considering only these 15 groups that had at least one presentation of the SNP. The frequency of the c.693+304G>A SNP in unbiased samples from breeds known to carry the SNP ranged from $0.078 \%$ in the Exotic Shorthair to $12.97 \%$ in the Bengal (Table 3). In submitted (biased) samples requesting PK deficiency testing (Table 4), the SNP frequency ranged from $0.0 \%$ in the Australian Mist cats to $41.4 \%$ in the Singapura breed from the UK. United States PK deficiency test requesting samples ranged from $11.75 \%$ in the Somali to $23.0 \%$ in the Singapuras.

For 13 of 15 groups with the PK deficiency associated SNP (Table 2) observed and expected genotypes based on the SNP frequency in the populations did not deviate significantly from expected Hardy -Weinberg ratios at 
Table 2 Pyruvate kinase deficiency allele frequencies in cat breeds and populations

\begin{tabular}{|c|c|c|c|c|c|c|c|c|}
\hline Breed & Samples & GG & GA & $\mathrm{AA}$ & Freq. A & Exp GG & Exp GA & $\operatorname{Exp} A A$ \\
\hline Abyssinian* & 1955 & 1476 & 465 & 14 & 0.126 & 1493 & 431 & 31 \\
\hline Abyssinian (UK) & 36 & 28 & 8 & 0 & 0.11 & 29 & 7 & 0 \\
\hline American Bobtail & 10 & 10 & & & 0 & & & \\
\hline American SH & 51 & 51 & & & 0 & & & \\
\hline American Wirehair & 11 & 11 & & & 0 & & & \\
\hline Australian Mist (UK) & 27 & 27 & & & 0 & & & \\
\hline Balinese & 39 & 39 & & & 0 & & & \\
\hline Bengal* & 1340 & 925 & 390 & 25 & 0.164 & 936 & 368 & 36 \\
\hline Bengal (UK) & 1210 & 827 & 354 & 29 & 0.17 & 834 & 341 & 35 \\
\hline Birman & 187 & 187 & & & 0 & & & \\
\hline British SH & 966 & 966 & & & 0 & & & \\
\hline British SH (UK) & 43 & 43 & & & 0 & & & \\
\hline Burmese & 118 & 118 & & & 0 & & & \\
\hline Burmilla & 38 & 38 & & & 0 & & & \\
\hline Cornish Rex & 46 & 46 & & & 0 & & & \\
\hline Devon Rex & 186 & 186 & & & 0 & & & \\
\hline Domestic SH/LH & 76 & 62 & 13 & 1 & 0.099 & 62 & 13 & 1 \\
\hline Egyptian Mau & 36 & 27 & 9 & 0 & 0.1 & 28 & 8 & 1 \\
\hline Exotic LH & 91 & 91 & & & 0 & & & \\
\hline Exotic SH & 645 & 644 & 1 & 0 & 0.0008 & 644 & 1 & 0 \\
\hline Himalayan & 601 & 601 & & & 0 & & & \\
\hline Korat & 41 & 41 & & & 0 & & & \\
\hline La Perm & 56 & 40 & 16 & 0 & 0.14 & 41 & 14 & 1 \\
\hline Maine Coon & 118 & 103 & 15 & 0 & 0.064 & 104 & 14 & 0 \\
\hline Munchkin & 19 & 19 & & & 0 & & & \\
\hline Norwegian Forest Cat & 13 & 10 & 3 & 0 & 0.1 & 10 & 3 & 0 \\
\hline Ocicat & 69 & 69 & & & 0 & & & \\
\hline Oriental LH & 48 & 48 & & & 0 & & & \\
\hline Oriental SH & 337 & 336 & 1 & 0 & 0.001 & 336 & 1 & 0 \\
\hline Persian & 2226 & 2217 & 9 & 0 & 0.002 & 2217 & 9 & 0 \\
\hline Ragamuffin & 20 & 20 & & & 0 & & & \\
\hline Ragdoll & 1063 & 1063 & & & 0 & & & \\
\hline Russian Blue & 14 & 14 & & & 0 & & & \\
\hline Savannah Cat & 11 & 10 & 1 & 0 & 0.05 & 10 & 1 & 0 \\
\hline Scottish Fold & 68 & 68 & & & & & & \\
\hline Selkirk Rex & 124 & 124 & & & & & & \\
\hline Siamese & 457 & 457 & & & & & & \\
\hline Siberian Cat & 377 & 360 & 16 & 1 & 0.024 & 359 & 18 & 0 \\
\hline Singapura & 150 & 88 & 55 & 7 & 0.23 & 89 & 53 & 8 \\
\hline Singapura (UK) & 168 & 60 & 77 & 31 & 0.414 & 58 & 81 & 29 \\
\hline Somali & 633 & 527 & 104 & 2 & 0.0853 & 530 & 99 & 5 \\
\hline Somali (UK) & 65 & 49 & 14 & 2 & 0.14 & 48 & 16 & 1 \\
\hline Sphynx & 248 & 248 & & & & & & \\
\hline Turkish Angora & 31 & 31 & & & & & & \\
\hline Unreported & 111 & 98 & 13 & 0 & 0.059 & 99 & 12 & 0 \\
\hline Total & 14179 & 12503 & 1564 & 112 & 0.063051 & 12447 & 1675 & 56 \\
\hline
\end{tabular}

*=breeds significantly deviating for Hardy-Weinberg expected ratios. 
Table 3 Unbiased PK deficiency allele frequencies in 12 cat breeds based on samples submitted for other genetic testing

\begin{tabular}{|c|c|c|c|c|c|c|c|c|}
\hline \multicolumn{9}{|c|}{ Non - PK deficiency submitted samples (unbiased) } \\
\hline Breed & $\#$ & GG & GA & $A A$ & Freq. A & Exp GG & $\operatorname{Exp} G A$ & $\operatorname{Exp} A A$ \\
\hline Abyssinian & 497 & 445 & 52 & 0 & 0.0523 & 447 & 49 & 1 \\
\hline Bengal & 320 & 242 & 73 & 5 & 0.130 & 242 & 72 & 5 \\
\hline Domestic SH/LH & 76 & 62 & 13 & 1 & 0.12 & 59 & 16 & 1 \\
\hline Egyptian Mau & 36 & 27 & 9 & 0 & 0.13 & 27 & 8 & 1 \\
\hline Maine Coon & 118 & 103 & 15 & 0 & 0.0636 & 103 & 14 & 0 \\
\hline Exotic SH & 645 & 644 & 1 & 0 & 0.000775 & 644 & 1 & 0 \\
\hline Norwegian Forest Cat & 13 & 10 & 3 & 0 & 0.12 & 10 & 3 & 0 \\
\hline Oriental SH & 337 & 336 & 1 & 0 & 0.00148 & 336 & 1 & 0 \\
\hline Persian & 2226 & 2217 & 9 & 0 & 0.002021 & 2217 & 9 & 0 \\
\hline Savannah & 11 & 10 & 1 & 0 & 0.046 & 10 & 1 & 0 \\
\hline Siberian & 377 & 360 & 16 & 1 & 0.0239 & 359 & 18 & 0 \\
\hline Somali & 227 & 213 & 14 & 0 & 0.0308 & 213 & 14 & 0 \\
\hline unreported & 111 & 98 & 13 & 0 & 0.0586 & 98 & 12 & 0 \\
\hline Total & 4994 & 4767 & 220 & 7 & 0.0234 & 4763 & 229 & 3 \\
\hline Total (-Per, OSh, ExSh) & 1786 & 1570 & 209 & 7 & 0.06234 & 1570 & 209 & 7 \\
\hline
\end{tabular}

$\mathrm{p}=0.05$. However, significant Hardy-Weinberg deviations were found for Bengals and Abyssinians at $\mathrm{p}=0.05$ and 0.001 , respectively but only for the US populations. Observed carriers were increased in the Bengals by $6.0 \%$, and homozygous affected individuals were decreased by $30.6 \%$. In Abyssinians, carriers increased by $7.9 \%$ while the observed homozygous affected cats decreased by $54.8 \%$. When considering the biased versus unbiased
Abyssinian and Bengal samples, the observed genotypes for the unbiased sample sets had Hardy-Weinberg predicted genotype ratios. However, the biased sample set significantly deviated at $\mathrm{p}=0.001$ for both data sets. The Abyssinians had a $10.4 \%$ increase in carrier cats and a $57.6 \%$ reduction in observed homozygous affected cats while Bengal cats had a $35.5 \%$ reduction in observed homozygous affected cats.

Table 4 Biased PK deficiency allele frequencies in six cat breeds based on samples submitted for PK testing

Samples submitted for PK deficiency testing (biased)

\begin{tabular}{|c|c|c|c|c|c|c|c|c|}
\hline Breed & $\#$ & GG & $\mathrm{GA}$ & AA & Freq. A & Exp GG & $\operatorname{Exp} G A$ & $\operatorname{Exp} A A$ \\
\hline Abyssinian* & 1458 & 1031 & 413 & 14 & 0.1512 & 1051 & 374 & 33 \\
\hline Abyssinian (UK) & 36 & 28 & 8 & 0 & 0.11 & 29 & 7 & 0 \\
\hline Abyssinian Total & 1494 & 1059 & 421 & 14 & 0.1492 & 1080 & 381 & 33 \\
\hline Aust Mist (UK) & 27 & 27 & 0 & 0 & 0.0 & 27 & 0 & 0 \\
\hline Bengal* & 1020 & 683 & 317 & 20 & 0.1750 & 694 & 295 & 31 \\
\hline Bengal (UK) & 1210 & 827 & 354 & 29 & 0.1702 & 833 & 342 & 35 \\
\hline Bengal Total & 2230 & 1510 & 671 & 39 & 0.1724 & 1527 & 637 & 66 \\
\hline La Perm & 56 & 40 & 16 & 0 & 0.1429 & 41 & 14 & 1 \\
\hline Singapura & 150 & 88 & 55 & 7 & 0.230 & 89 & 53 & 8 \\
\hline Singapura (UK) & 168 & 60 & 77 & 31 & 0.414 & 58 & 81 & 29 \\
\hline Singapura Total & 318 & 148 & 132 & 38 & 0.327 & 147 & 134 & 37 \\
\hline Somali & 400 & 308 & 90 & 2 & 0.118 & 311 & 83 & 6 \\
\hline Somali (UK) & 65 & 49 & 14 & 2 & 0.14 & 48 & 16 & 1 \\
\hline Somali Total & 465 & 357 & 104 & 4 & 0.120 & 359 & 99 & 7 \\
\hline Total US & 3084 & 2150 & 891 & 43 & 0.1584 & 2186 & 819 & 79 \\
\hline Total UK & 1506 & 991 & 453 & 62 & 0.1916 & 968 & 446 & 65 \\
\hline Total & 4590 & 3141 & 1344 & 105 & 0.1693 & 3113 & 1251 & 143 \\
\hline
\end{tabular}

*=breeds significantly deviating from Hardy-Weinberg expected ratios. 


\section{Discussion}

Glycolysis is one of the principal pathways of energy (ATP) generation in cells. In erythrocytes, glycolysis is the only pathway for ATP synthesis since mature red cells lack mitochondria. The most frequent glycolytic abnormality is PK deficiency. In humans, most mutations are located in the coding sequences of PKLR, with missense, deletions, insertions, splice defects, premature stop codons and promoter mutations, being common. Humans, mice, dogs and cats have been documented to have PK deficiency [22,23,25,27,29,32,41-43]. In cats, the disease was first reported in Abyssinians and their longhaired morph, the Somali, as well as in random bred cats $[31,32]$. Subsequent to the reports in Abyssinians, breeders and veterinarians have suggested that additional breeds demonstrate the hallmarks of Abyssinian PK deficiency by requesting the PK deficiency test from the service laboratories.

In a 2005 detailed review, Zanella et al. [20] determined that 158 novel human PKLR mutations had been identified. Subsequent population studies have increased this total by over 44 novel mutations $[18,44]$. Mutations are found in every exon, as well as several introns, all of which result in human PK deficiency. The domestic cat PKLR type-R CDS transcript has similar genetic sequence and structure to other mammalian species, with $\sim 88 \%$ homology at both the DNA and protein sequence level. Between species polymorphisms are distributed across the transcript. This study demonstrated that cats with PK deficiency produce transcripts with a $13 \mathrm{bp}$ deletion at the $3^{\prime}$ end of exon 5 of PKLR, however the altered form was only confirmed in the R-type transcript found in liver, bone marrow and blood. The deletion results in the loss of $57 \%$ of the mature protein, likely resulting in the disease phenotype. The only identified and correlated genomic mutation is a guanine to adenine transition in intron 5, $304 \mathrm{bp} \mathrm{3'}$ of the exon 5 splicedonor site and $53 \mathrm{bp}$ upstream from the exon 6 spliceacceptor site. The mechanism by which this mutation results in the erroneous splicing of exons 5 and 6 has yet to be determined. Several splice site variants have been noted in human PK deficiency patients, and how these affect splicing has not always been identified $[45,46]$. For example, the effect of mutation IVS9 $+43 \mathrm{c}$ on the mRNA splicing cannot be directly demonstrated because the aberrant mRNA transcript cannot be obtained. However, the IVS9 +43c mutation is likely to be involved in PK deficiency since the mutation is not found in normal human populations, in silico splicing prediction suggests introduction of a new acceptor splice site, and no other sequence abnormalities were detected in the patient's DNA [16]. Moreover, mutations in internal portions of exons or introns, which result in aberrant splicing, have been described in several disease-related genes $[47,48]$.
PK activity in the erythrocytes of carrier cats is estimated as $50 \%$ the level of activity of the wild type [32] yet the frequency in the random population may suggest some selective advantage for cats with the mutation such as blood -borne parasite infection resistance. Homozygous cats that should have disease-associated presentations, such as splenomegaly, hemolytic anemia and increased osmotic fragility of erythrocytes, are not being actively reported by Bengal, Singapura and other breed owners to the veterinary community possibly owing to the fact that the disease can be episodic, mild and subclinical [30]. In addition, the fact that expression of the disease phenotype is variable both in the age of onset and severity suggests that additional factors may be required to induce disease, such as stress and activity level [30]. Never the less, the lack of presentation of sick cats is puzzling, prompting further investigation of the c.693+304G>A PK deficiency-associated SNP.

PK deficiency was first documented in an Abyssinian from the USA [32], and later in Abyssinian and Somali cats in Germany and Australia $[49,50]$. A limited Australian population study in Abyssinian and Somali cats $(\mathrm{N}=60)$ revealed a frequency of 0.13 and 0.29 , respectively, of the intronic SNP [34]. However, the authors noted that, although multiple breeders were approached for inclusion, participation may have been biased towards those with known carrier cats. Additionally, related cats, including full siblings, were used. Thus, the estimation of prevalence in Australia may be significantly biased towards the affected allele. Abyssinian and Bengal breeders have been actively screening for the disease-associated SNP and represent over $81 \%$ of samples submitted for PK deficiency testing. The c.693+304G>A PK deficiency-associated SNP allele frequency deviates from Hardy-Weinberg equilibrium $(\mathrm{p}=0.05)$ (Table 2) only in these two breeds. The Abyssinians, which have been tested for PK deficiency over the longest interval, have a significant deficit from the predicted numbers of homozygous affected cats. The Bengals also have a decrease in the observed numbers of homozygous affected cats, although to a lesser extent. Increases in the observed number of carriers in both breeds would suggest that breeders are using genetic data to actively select against matings that would produce affected offspring. Moreover, lack of selection against the deleterious allele in the remaining populations has allowed the c.693 +304G > A PK deficiency-associated SNP to persist and results in higher percentages of affected cats in those breeds.

In this study, the frequency of the c.693+304G>A PK deficiency-associated SNP ranged from $3-15 \%$ in Abyssinian and Somalis between the USA and UK. Although Abyssinian and Somali breeders have known of the health concern, no genetic test has been peer-reviewed and published to ensure widespread detection of the 
mutation. Consequently, in an unbiased sampling of cats, the frequency of the c.693+304G $>$ A PK deficiencyassociated SNP is $\sim 13 \%$ in Bengals and Egyptian Maus, two breeds that have used Abyssinians in their breed development, and perhaps would have benefitted from better knowledge of the potential of PK deficiency concerns. The c.693+304G>A PKLR SNP is at a critically high level in the Singapura with nearly $42 \%$ of UK tested cats having the SNP. This sampling is likely biased as breeders with concerns for the disease are submitting cat samples for testing. However, the frequency in Bengals in the UK (16\%) is similar to the USA (18\%) and nearly the same for unbiased Bengal sampling in the USA (13\%). The Singapura is also a breed developed from Abyssinian stock [51]. Thus, the introgression of the disease into so many distinct breeds is not enigmatic. In Singapuras, the SNP frequency (32.7\%) is 2.6-fold greater than that of the remainder of the affected breeds (12.47\%). The Singapura is numerically one of the smallest breeds and the high frequency likely results from either a probable high frequency of the c.693 $+304 \mathrm{G}>\mathrm{A}$ PKLR SNP in the founder population or accidental high inbreeding of affected cats during the breeds inception in the 1970's. Lack of a diagnostic test in the early stages of breed development and later, failure to disclose the genetic marker correlated with the disease undeniably contributed to the spread of the affected allele via breed development programs.

The western breeds, Norwegian Forest cats, Siberians and Maine Coons, are derived from regional feral populations in Scandinavia, Russia and the USA, respectively. Considering the most probable explanation of identity by decent, the presence of the c.693+304G>A PKLR SNP in these three breeds presents an interesting conundrum regarding its origin. The SNP is present in random bred cats $(11 \%$ in 76 cats). It is possible that random bred founder cats or local feral cats used in breed expansion carried the allele. It is equally likely that a desirable phenotype from an affected breed was introduced into these populations and the affected allele was inadvertently introduced as well.

The c.693+304G>A PKLR SNP allele frequency varied across the populations evaluated. Samples representing 25 groups did not possess the SNP. Breeds such as the Persians, Exotic and Oriental shorthairs had frequencies less than 0.002 , a 10 -fold lower frequency than found in the next lowest breed, the Siberian. The nine carrier Persian samples were provided by breeders from Japan (3), Chile (2), England (3) and the Netherlands (1) and each set contained full siblings, Netherlands excepted. Intentional or inadvertent incorrect breed designation by owners on submission forms may account for the presence of c.693+304G>A PKLR SNP in some breeds. Some breeders have acknowledged providing incorrect breed identification when submitting samples for testing to circumvent commercial laboratory rules limiting availability of tests that have not been validated for a specific breed. Thus, the breeds with extremely low frequencies may not actually have affected alleles within their populations.

The entire PKLR type- $\mathrm{R}$ transcript has now been sequenced. The lone transcript variant observed between affected and wild-type alleles is a 13 bp deletion at the 3 ' end of exon 5. This mutation is correlated with an intronic c.693+304G $>$ A mutation. No other potentially causative mutation was identified although two additional intron 5 mutations are in close proximity to the causative mutation. Of particular interest is the British Shorthair c. $693+303 \mathrm{C}>\mathrm{T}$ mutation, located $1 \mathrm{bp}$ from the correlated mutation (Figure 2), which is present at a frequency of $27.9 \%$ but has no disease association. Thus, both the nature and location of the c.693+304G $>$ A may be critical for disease presentation.

\section{Conclusions}

This study presents an extensive survey for the presence and frequency of the c.693+304G>A PK deficiencyassociated SNP in 38 domestic cat breeds with 12 breeds ranging from $2-16 \%$ for the SNP. Based upon allelic frequency in random unbiased population sampling, PK testing is recommended for several breeds including Bengals, Egyptian Maus, La Perms, Maine Coon cats, Norwegian Forest cats, Savannahs, Siberians, and Singapuras, in addition to Abyssinians and Somalis. Breeds known to have been derived from Abyssinian crosses such as the Ocicat and novel breed development or out-crossing programs using Bengals or other affected breeds should test as well. Future expanded testing will undeniably help prevent breeding affected individuals and possibly allow selective elimination of the c.693+304G>A PK deficiencyassociated SNP in domestic cat populations.

\section{Abbreviations \\ PK: Protein Kinase; PKLR: Pyruvate Kinase, Liver and Red Blood Cell; SNP: Single Nucleotide Polymorphism; ATP: Adenosine Triphosphate; PKM2 Pyruvate Kinase: Muscle; dNTP: Deoxynucleotide Triphosphate; CDNA: Complementary Deoxyribonucleic Acid; RNA: Ribonucleic Acid; mRNA: Messenger Ribonucleic Acid; RBC: Red Blood Cell; VGL: Veterinary Genetics Laboratory; LVS: Langford Veterinary Services; CA: California; UK: United Kingdom; USA: United States of America.}

\section{Competing interests}

The authors declare that they have no competing interests.

\section{Authors' contributions}

RAG performed the assays, sequenced the gene and cDNA and wrote the manuscript; JCG contributed to technical aspects of the manuscript and provided initial cross-breed data; MCTP and CRH coordinated sample assessment from service laboratories and edited the manuscript; LAL edited the manuscript. All authors read and approved the final manuscript.

\section{Acknowledgments}

The authors wish to thank Shannon Joslin for technical assistance, Dr. Barbara Gandolfi for RACE consultation, Dr. Niels C. Pedersen for feline disease consultation, Shayne Hughes for data management and the entire 
technical staff at the VGL and LVS. This project was supported by partial funding provided by the National Institutes of Health - National Center for Research Resources (R24 RR016094) and is currently supported by the Office of Research Infrastructure Programs/OD R24OD010928.

\section{Author details}

${ }^{1}$ Department of Population Health and Reproduction, School of Veterinary Medicine, University of California, Davis, CA 95616, USA. ² Veterinary Genetics Laboratory, School of Veterinary Medicine, University of California, Davis, CA 95616, USA. ${ }^{3}$ Molecular Diagnostic Unit, Langford Veterinary Services, University of Bristol, Langford BS40 5DU, UK.

Received: 15 August 2012 Accepted: 22 October 2012

Published: 30 October 2012

\section{References}

1. Simpson CF, Kling JM: The mechanism of denucleation in circulating erythroblasts. J of Cell Biol 1967, 35(1):237-245.

2. Repasky EA, Eckert BS: A reevaluation of the process of enucleation in mammalian erythroid cells. Prog in Clin and Biol Res 1981, 55:679-692.

3. Saheki S, Saheki K, Tanaka T: Peptide structures of pyruvate kinase isozymes. I. Comparison of the four pyruvate kinase isozymes of the rat. Biochim Biophys Acta 1982, 704(3):484-493.

4. Marie J, Simon MP, Dreyfus JC, Kahn A: One gene, but two messenger RNAs encode liver $L$ and red cell $L '$ pyruvate kinase subunits. Nature 1981, 292(5818):70-72.

5. Marie J, Levin MJ, Simon MP, Kahn A: Genetic and epigenetic control of the pyruvate kinase isozymes in mammals. Isozymes Curr Top Biol Med Res 1983, 7:221-240

6. Tsutsumi H, Tani K, Fujii H, Miwa S: Expression of L- and M-type pyruvate kinase in human tissues. Genomics 1988, 2(1):86-89.

7. Fothergill-Gilmore LA, Michels PA: Evolution of glycolysis. Prog in Biophys and Mol Biol 1993, 59(2):105-235.

8. Kahn A, Marie J: Pyruvate kinases from human erythrocytes and liver. Meth in Enzymology 1982, 90:131-140.

9. Lacronique V, Boquet D, Lopez S, Kahn A, Raymondjean M: In vitro and in vivo protein-DNA interactions on the rat erythroid-specific L' pyruvate kinase gene promoter. Nucl Acids Res 1992, 20(21):5669-5676

10. Tani K, Fujii H, Nagata S, Miwa S: Human liver type pyruvate kinase: complete amino acid sequence and the expression in mammalian cells. Proc Natl Acad Sci U S A 1988, 85(6):1792-1795.

11. Corcoran E, Phelan JJ, Fottrell PF: Purification and properties of pyruvate kinase from human lung. Biochim Biophys Acta 1976, 446(1):96-104

12. Noguchi T, Yamada K, Inoue H, Matsuda T, Tanaka T: The L- and R-type isozymes of rat pyruvate kinase are produced from a single gene by use of different promoters. J Biol Chem 1987, 262(29):14366-14371.

13. Baronciani L, Beutler E: Molecular study of pyruvate kinase deficient patients with hereditary nonspherocytic hemolytic anemia. J of Clin Invest 1995, 95(4):1702-1709.

14. Baronciani L, Zanella A, Bianchi P, Zappa M, Alfinito F, Iolascon A, Tannoia N, Beutler E, Sirchia G: Study of the molecular defects in glucose phosphate isomerase-deficient patients affected by chronic hemolytic anemia. Blood 1996, 88(6):2306-2310.

15. Beutler E, Baronciani L: Mutations in pyruvate kinase. Hum Mut 1996 , $7(1): 1-6$

16. Fermo E, Bianchi P, Chiarelli LR, Cotton F, Vercellati C, Writzl K, Baker K, Hann I, Rodwell R, Valentini G, et al: Red cell pyruvate kinase deficiency: 17 new mutations of the PK-LR gene. Br J Haematol 2005, 129(6):839-846.

17. Miwa S, Fujii H: Molecular basis of erythroenzymopathies associated with hereditary hemolytic anemia: tabulation of mutant enzymes. Am J of Hematol 1996, 51(2):122-132.

18. Pissard S, Max-Audit I, Skopinski L, Vasson A, Vivien P, Bimet C, Goossens M, Galacteros F, Wajcman H: Pyruvate kinase deficiency in France: a 3-year study reveals 27 new mutations. Br J Haematol 2006, 133(6):683-689.

19. Rouger H, Valentin C, Craescu CT, Galacteros F, Cohen-Solal M: Five unknown mutations in the LR pyruvate kinase gene associated with severe hereditary nonspherocytic haemolytic anaemia in France. $\mathrm{Br} J$ Haematol 1996, 92(4):825-830.

20. Zanella A, Fermo E, Bianchi P, Valentini G: Red cell pyruvate kinase deficiency: molecular and clinical aspects. Br J Haematol 2005, 130(1):11-25.
21. Kanno H, Fujii H, Hirono A, Miwa S: cDNA cloning of human R-type pyruvate kinase and identification of a single amino acid substitution (Thr384--Met) affecting enzymatic stability in a pyruvate kinase variant (PK Tokyo) associated with hereditary hemolytic anemia. Proc Natl Acad Sci U S A 1991, 88(18):8218-8221.

22. Giger U, Noble NA: Determination of erythrocyte pyruvate kinase deficiency in Basenjis with chronic hemolytic anemia. J Am Vet Med Assoc 1991, 198(10):1755-1761.

23. Giger U, Mason GD, Wang P: Inherited erythrocyte pyruvate kinase deficiency in a beagle dog. Vet Clin Path / Am Soc for Vet Clin Path 1991, 20(3):83-86.

24. Mhaskar Y, Harvey JW, Dunaway GA: Developmental changes of 6 phosphofructo-1-kinase subunit levels in erythrocytes from normal dogs and dogs affected by glycogen storage disease type VII. Comp Biochem and Physiol B, Comp Biochem 1992, 101(3):303-307.

25. Schaer M, Harvey JW, Calderwoodmays M, Giger U: Pyruvate kinase deficiency causing hemolytic anemia with secondary hemochromatosis in a Cairn Terrier. J of the Am An Hosp Assoc 1992, 28:233-239.

26. Inal Gultekin G, Raj K, Foureman P, Lehman S, Manhart K, Abdulmalik O, Giger U: Erythrocytic Pyruvate Kinase Mutations Causing Hemolytic Anemia, Osteosclerosis, and Secondary Hemochromatosis in Dogs. J of Vet Int Med/ Am Col of Vet Int Med 2012, 26:935-944.

27. Chapman BL, Giger U: Inherited erythrocyte pyruvate kinase deficiency in the West Highland White Terrier. J of Sm An Prac 1990, 31:610-616.

28. Whitney KM, Lothrop CD Jr: Genetic test for pyruvate kinase deficiency of Basenjis. J Am Vet Med Assoc 1995, 207(7):918-921.

29. Skelly BJ, Wallace M, Rajpurohit YR, Wang P, Giger U: Identification of a 6 base pair insertion in West Highland White Terriers with erythrocyte pyruvate kinase deficiency. Am J Vet Res 1999, 60(9):1169-1172.

30. Kohn B, Fumi C: Clinical course of pyruvate kinase deficiency in Abyssinian and Somali cats. J Feline Med Surg 2008, 10(2):145-153.

31. Kohn B, Goldschmidt MH, Hohenhaus AE, Giger U: Anemia, splenomegaly, and increased osmotic fragility of erythrocytes in Abyssinian and Somali cats. J Am Vet Med Assoc 2000, 217(10):1483-1491.

32. Ford S, Giger U, Duesberg C, Beutler E, Wang P: Inherited erythrocyte pyruvate kinase deficiency causing hemolytic anemia in an Abyssinian cat. J Vet Int Med 1992, 6:123.

33. Giger U, Rajpurohit Y, Wang P, Ford S, Kohn B, Patterson DF, Beutler E, Henthorn PS: Molecular basis of erythrocyte pyruvate kinase (PK) deficiency in cats [abstract]. Blood 1997, 90:5

34. Barrs VR, Giger U, Wilson B, Chan CT, Lingard AE, Tran L, Seng A, Canfield PJ, Beatty JA: Erythrocytic pyruvate kinase deficiency and $A B$ blood types in Australian Abyssinian and Somali cats. Aust Vet J 2009, 87(1):39-44

35. Tarditi CR, Grahn RA, Evans JJ, Kurushima JD, Lyons LA: Mitochondrial DNA sequencing of cat hair: an informative forensic tool. J of Forensic Sci 2011, 56(Suppl 1):S36-S46.

36. Helps CR, Tasker S, Barr FJ, Wills SJ, Gruffydd-Jones TJ: Detection of the single nucleotide polymorphism causing feline autosomal-dominant polycystic kidney disease in Persians from the UK using a novel realtime PCR assay. Mol and Cell Probes 2007, 21(1):31-34.

37. Bighignoli B, Niini T, Grahn RA, Pedersen NC, Millon LV, Polli M, Longeri M, Lyons LA: Cytidine monophospho-N-acetylneuraminic acid hydroxylase (CMAH) mutations associated with the domestic cat $A B$ blood group. BMC Gen 2007, 8:27.

38. Pontius JU, Mullikin JC, Smith DR, Lindblad-Toh K, Gnerre S, Clamp M, Chang J, Stephens R, Neelam B, Volfovsky N, et al: Initial sequence and comparative analysis of the cat genome. Gen Res 2007, 17(11):1675-1689.

39. Grahn R, Ellis MR, Grahn JC, Lyons L: A novel CYP27B1 mutation causes a feline vitamin D-dependent rickets type IA. J Feline Med Surg 2012, 14(8):587-590

40. Grahn RA, Kurushima JD, Billings NC, Grahn JC, Halverson JL, Hammer E, Ho CK, Kun TJ, Levy JK, Lipinski MJ, et al: Feline non-repetitive mitochondrial DNA control region database for forensic evidence. Forensic Sci Int Gen 2011, 5(1):33-42.

41. Searcy GP, Miller DR, Tasker JB: Congenital hemolytic anemia in the Basenji dog due to erythrocyte pyruvate kinase deficiency. Can J of Comp Med/ Revue Can de Med Comp 1971, 35(1):67-70

42. Valentine WN: Deficiencies associated with Embden-Meyerhof pathway and other metabolic pathways. Sem in Hem 1971, 8(4):348-366. 
43. Morimoto $M$, Kanno $H$, Asai $H$, Tsujimura T, Fujii H, Moriyama $Y$, Kasugai T, Hirono A, Ohba Y, Miwa S, et al: Pyruvate kinase deficiency of mice associated with nonspherocytic hemolytic anemia and cure of the anemia by marrow transplantation without host irradiation. Blood 1995, 86(11):4323-4330.

44. Kedar P, Hamada T, Warang P, Nadkarni A, Shimizu K, Fujij H, Ghosh K, Kanno H, Colah R: Spectrum of novel mutations in the human PKLR gene in pyruvate kinase-deficient Indian patients with heterogeneous clinical phenotypes. Clin Gen 2009, 75(2):157-162.

45. van Wijk R, van Solinge WW, Nerlov C, Beutler E, Gelbart T, Rijksen G, Nielsen FC: Disruption of a novel regulatory element in the erythroidspecific promoter of the human PKLR gene causes severe pyruvate kinase deficiency. Blood 2003, 101(4):1596-1602

46. Zanella A, Bianchi P, Baronciani L, Zappa M, Bredi E, Vercellati C, Alfinito F, Pelissero G, Sirchia G: Molecular characterization of PK-LR gene in pyruvate kinase-deficient Italian patients. Blood 1997, 89(10):3847-3852.

47. Cartegni L, Chew SL, Krainer AR: Listening to silence and understanding nonsense: exonic mutations that affect splicing. Nat Rev Gen 2002, 3(4):285-298.

48. Coutinho G, Xie J, Du L, Brusco A, Krainer AR, Gatti RA: Functional significance of a deep intronic mutation in the ATM gene and evidence for an alternative exon 28a. Hum Mut 2005, 25(2):118-124.

49. Kohn B, Fumi C, Seng A, Giger U: Anemia due to erythrocytic pyruvate kinase deficiency in Somali and Abyssinian cats in Germany. Kleintierpraxis 2005, 50:305-312.

50. Mansfield CS, Clark P: Pyruvate kinase deficiency in a Somali cat in Australia. Aust Vet J 2005, 83(8):483-485.

51. Morris D: Cat breeds of the world: a complete illustrated encyclopedia. New York, New York: Viking Press; 1999.

doi:10.1186/1746-6148-8-207

Cite this article as: Grahn et al:: Erythrocyte Pyruvate Kinase Deficiency mutation identified in multiple breeds of domestic cats. BMC Veterinary Research 2012 8:207.

\section{Submit your next manuscript to BioMed Central and take full advantage of:}

- Convenient online submission

- Thorough peer review

- No space constraints or color figure charges

- Immediate publication on acceptance

- Inclusion in PubMed, CAS, Scopus and Google Scholar

- Research which is freely available for redistribution 